\title{
Microstructure and Mechanical Properties of $\mathrm{Ti}(\mathrm{Cr}) \mathrm{SiC}(0) \mathrm{N}$ Coatings Deposited by Plasma Enhanced Magnetron Sputtering
}

\author{
Xin Xin, Zhang Tengfei, Wang Yu, Yu Yan, Leng Yongxiang, Xie Dong, \\ Huang Nan
}

Key Laboratory of Advanced Technologies of Materials, Ministry of Education, Southwest Jiaotong University, Chengdu 610031, China

\begin{abstract}
TiSiCN, TiSiCON, TiCrSiCN, TiCrSiCON, CrSiCN and CrSiCON coatings have been deposited on WC-Co substrates and Si wafers using plasma enhanced magnetron sputtering (PEMS) technique. The microstructure, composition and mechanical properties of the non-oxygen coatings and oxygen-containing coatings were studied by XRD, SEM, EDS and load-depth-sensing indentation. The tribological behavior of the coatings against $\mathrm{Al}_{2} \mathrm{O}_{3}$ balls was conducted by pin-on-disc tests. The results show that TiSiCON, TiCrSiCON and CrSiCON coatings exhibit the face center cubic (fcc) TiN-type (or CrN-type) structure. The existence of oxygen will induce loose structure and more defects for TiSiCON, TiCrSiCON and CrSiCON coatings compared with TiSiCN, TiCrSiCN and $\mathrm{CrSiCN}$, respectively. The addition of oxygen element would lead to the decrease of the hardness $(H)$ and elasticity of $\mathrm{Ti}(\mathrm{Cr}) \mathrm{SiCN}$ coatings. TiCrSiCON and $\mathrm{CrSiCON}$ coatings with oxygen element have lower friction coefficients and wear rate compared with $\mathrm{TiCrSiCN}$ and $\mathrm{CrSiCN}$ coatings without oxygen, respectively. The TiSiCON with higher friction coefficient and wear rate shows poor abrasive wear resistance than TiSiCN.
\end{abstract}

Key words: $\mathrm{Ti}(\mathrm{Cr}) \mathrm{SiC}(\mathrm{O}) \mathrm{N}$; oxygen-containing coatings; microstructure; wear; mechanical properties

Nanocomposite TiSiN coatings show many improved properties, such as high hardness, excellent oxidation resistance (up to $800{ }^{\circ} \mathrm{C}$ ), high temperature stability (up to $1000^{\circ} \mathrm{C}$ ) and wear resistance in comparison with conventional TiN and TiC coatings due to the unique microstructure with nano-sized TiN crystallites embedded in amorphous $\mathrm{Si}_{3} \mathrm{~N}_{4}$ matrix ${ }^{[1-3]}$. Based on this prototype of TiSiN, other transition metals (such as $\mathrm{Cr}, \mathrm{Ti}, \mathrm{W}, \mathrm{V}$ ) can also form Me-Si-N (Me refer to transition metal) coatings with the nanocomposite microstructure and excellent mechanical properties ${ }^{[4,5]}$. Because of these promising properties, the industrial applications of Me-Si-N nanocomposite coatings on machining, stamping and forming tools have been concerned by researchers and companies and these have acquired encouraging progress ${ }^{[6,7]}$.
The structure and properties of $\mathrm{Me}-\mathrm{Si}-\mathrm{N}$ nanocomposite coatings are affected by the element composition and the fraction. The content of Si element in $\mathrm{Me}-\mathrm{Si}-\mathrm{N}$ nanocomposite coatings will affect the properties of the coatings. The $\mathrm{Si}$ element can exist in solid solutions ${ }^{[8]}$ and amorphous $\mathrm{Si}_{3} \mathrm{~N}_{4}$ phase $^{[9]}$, even free $\mathrm{Si}$ when the $\mathrm{Si}$ content above 17 at ${ }^{[10]}$. Generally, when the Si content reach 3 at\% 12 at ${ }^{[11]}$, the coatings will exhibit the highest hardness and good oxidation resistance, while the specific threshold content value will vary with different deposition conditions.

The enhancing effect of oxygen element on the properties of Me-N coatings was widely researched ${ }^{[12,13]}$. But the researches about the addition of oxygen element in Me-Si-N coatings were controversial ${ }^{[14,15]}$. Veprek et al. ${ }^{[14]}$ believed that oxygen element existed as impurities in TiSiN coatings, and

$\overline{\text { Received date: July 14, } 2016}$

Foundation item: National Scholastic Athletics Foundation (U1330113); National Natural Science Foundation of China (81271953); Technology Project from Chongqing Science and Technology Commission (cstc2013jcyjA50036)

Corresponding author: Leng Yongxiang, Ph. D., Professor, Key Laboratory of Advanced Technologies of Materials, Ministry of Education, School of Materials Science and Engineering, Southwest Jiaotong University, Chengdu 610031, P. R. China, Tel: 0086-28-87601149, E-mail: yxleng@263.net 
the hardness of coatings would decrease significantly with the content of oxygen over 0.5 at $\%$. Nonetheless, some studies indicated that the incorporation of $\mathrm{O}$ may promote the properties of Me-Si-N coatings ${ }^{[15]}$.

In our previous research, the non-oxygen $\mathrm{TiSiCN}$, $\mathrm{TiCrSiCN}$ and $\mathrm{CrSiCN}$ coatings were comparatively studied with respect to their microstructure, adhesion properties and tribological behavior against Ti6Al4V ball ${ }^{[16]}$. The results showed that the $\mathrm{TiCrSiCN}$ coating had higher hardness than $\mathrm{CrSiCN}$, better adhesive properties than TiSiCN and lower wear rate against Ti6Al4V than the other two coatings.

In the present paper, oxygen element was added into three metal matrix coatings (Ti-based TiSiCN, Cr-based $\mathrm{CrSiCN}$ and TiCr-based $\mathrm{TiCrSiCN}$ ). The comparative study of microstructure and mechanical properties between non-oxygen and oxygen-containing coatings (TiSiCN vs. TiSiCON, TiCrSiCN vs. TiCrSiCON and $\mathrm{CrSiCN}$ vs. $\mathrm{CrSiCON}$ ) were conducted. The effects of oxygen element on the microstructure, hardness and wear behavior against $\mathrm{Al}_{2} \mathrm{O}_{3}$ of these three metal matrix coatings were investigated.

\section{Experiment}

TiSiCN, TiSiCON, TiCrSiCN, TiCrSiCON, CrSiCN and CrSiCON coatings were deposited on K40UF cemented carbide and silicon (100) wafer by plasma enhanced magnetron sputtering (PEMS) ${ }^{[17]}$. The Ar ion sputtering cleaning was conducted before the coating deposition. Then the coatings were produced in a gas mixture of $\operatorname{Ar}(150$ $\mathrm{mL} / \mathrm{min})$ and $\mathrm{N}_{2}(50 \mathrm{~mL} / \mathrm{mim})$. The substrate bias voltage was set at $-40 \mathrm{~V}$. The Si element was introduced by the gas of trimethylsilane $\left(\left(\mathrm{CH}_{3}\right)_{3} \mathrm{SiH}, \mathrm{TMS}\right)$. For the O-containing coatings (TiSiCON, TiCrSiCON, CrSiCON), the extra O element was doped by adding hexamethyldisiloxane (HMDSO) vapor. Two targets were employed simultaneously as the source of metal element for each sample. The deposition process was described in previous studies ${ }^{[16]}$. The detailed deposition parameters are shown in Table 1.

The wear loss of the wear tracks were measured by a surface profilometer (AMBIOS XP-2) and then the volume wear rate of coatings were calculated by the conventional formula refer to Li's research ${ }^{[16]}$. The morphology of wear tracks was studied by an optical microscope (Axio Lab.A1,
ZEISS, Germany).

Coating phase structure was characterized by X-ray diffraction (Philips X'Pert X) with a $\mathrm{Cu} \mathrm{K} \alpha$ source and the scanning scope was performed from $20^{\circ}$ to $70^{\circ}$ at a glancing angle of $2^{\circ}$. The morphology of surface and cross-section was characterized by scanning electron microscopy (SEM) (JEOL JSM-7001F) and the chemical compositions of the coatings were measured with energy dispersive X-ray spectroscopy (EDS). The chemical bonding state of two oxygen-containing coatings TiSiCON and $\mathrm{CrSiCON}$ was performed by X-ray photoelectron spectra (XPS) with $\mathrm{Al} \quad \mathrm{K} \alpha$ radiation (PerkinElmer PHI-5702). The samples was sputtered by Ar ion to eliminate surface contaminants for $100 \mathrm{~s}$.

The coating indentation hardness $(H)$ and indentation elastic modulus $(E)$ were measured by load-depth-sensing indentation method using an ultra-micro-hardness tester (Shimadzu DUH 211S, Japan) with a Vickers indenter under the maximum indentation load of $100 \mathrm{mN}$. The indentation elastic modulus was calculated from the slope of the unloading curve which was comparable with the Young's modulus of the material ${ }^{[18]}$. The final values and errors were determined from more than 10 indentations.

The tribological properties (wear and friction) were determined in dry sliding conditions using a pin-on-disc test from a CSEM tribometer (CSEM Instrument, Switzerland) at a load of $5 \mathrm{~N}$ and sliding speed of $3 \mathrm{~cm} / \mathrm{s}$. Alumina $\left(\mathrm{Al}_{2} \mathrm{O}_{3}\right)$ balls with $6 \mathrm{~mm}$ diameter were employed as the counter materials in wear testing of coatings. The sliding test was conducted for 20000 laps and the total sliding distance was about $376.8 \mathrm{~m}$.

\section{Results}

\subsection{Surface and cross sectional morphology}

Fig.1 and Fig.2 show the surface (the non-oxygen coatings ${ }^{[16]}$ ) and cross-sectional morphology of these six $\mathrm{Ti}(\mathrm{Cr}) \mathrm{SiC}(\mathrm{O}) \mathrm{N}$ coatings deposited on $\mathrm{Si}$ substrates, respectively. TiSiCN, TiSiCON, TiCrSiCN, TiCrSiCON, CrSiCN coatings exhibit cauliflower-like microstructure $^{[17]}$ of the surface, while for the CrSiCON coating, the cauliflowers are more independent with lots of gaps. The cross-sectional morphologies (Fig.2) show that the coating thickness varies from $4 \sim 11 \mu \mathrm{m}$ and declare clearly the columnar growth pattern of all the samples.

Table 1 Detailed deposition parameters of six tapy coatings of six kind coatings

\begin{tabular}{|c|c|c|c|c|c|c|c|c|}
\hline \multirow{2}{*}{ Coatings } & \multirow{2}{*}{ Target 1} & \multirow{2}{*}{ Power/kW } & \multirow{2}{*}{ Target 2} & \multirow{2}{*}{ Power/kW } & \multicolumn{3}{|c|}{ Gas flow $/ \mathrm{mL} \cdot \mathrm{mim}^{-1}$} & \multirow{2}{*}{ Time/h } \\
\hline & & & & & TMS & HMDSN & HMDSO & \\
\hline TiSiCN & $\mathrm{Ti}$ & 4 & $\mathrm{Ti}$ & 4 & & 3.5 & & 1.0 \\
\hline TiSiCON & $\mathrm{Ti}$ & 4 & $\mathrm{Ti}$ & 4 & & & 3.5 & 1.5 \\
\hline $\mathrm{TiCrSiCN}$ & $\mathrm{Ti}$ & 4 & $\mathrm{Cr}$ & 2 & 7.5 & 3.4 & & 1.0 \\
\hline TiCrSiCON & $\mathrm{Ti}$ & 4 & $\mathrm{Cr}$ & 4 & & & 3.5 & 1.5 \\
\hline $\mathrm{CrSiCN}$ & $\mathrm{Cr}$ & 2 & $\mathrm{Cr}$ & 2 & & 3 & & 1.0 \\
\hline $\mathrm{CrSiCON}$ & $\mathrm{Cr}$ & 2 & $\mathrm{Cr}$ & 2 & & & 3.5 & 1.5 \\
\hline
\end{tabular}




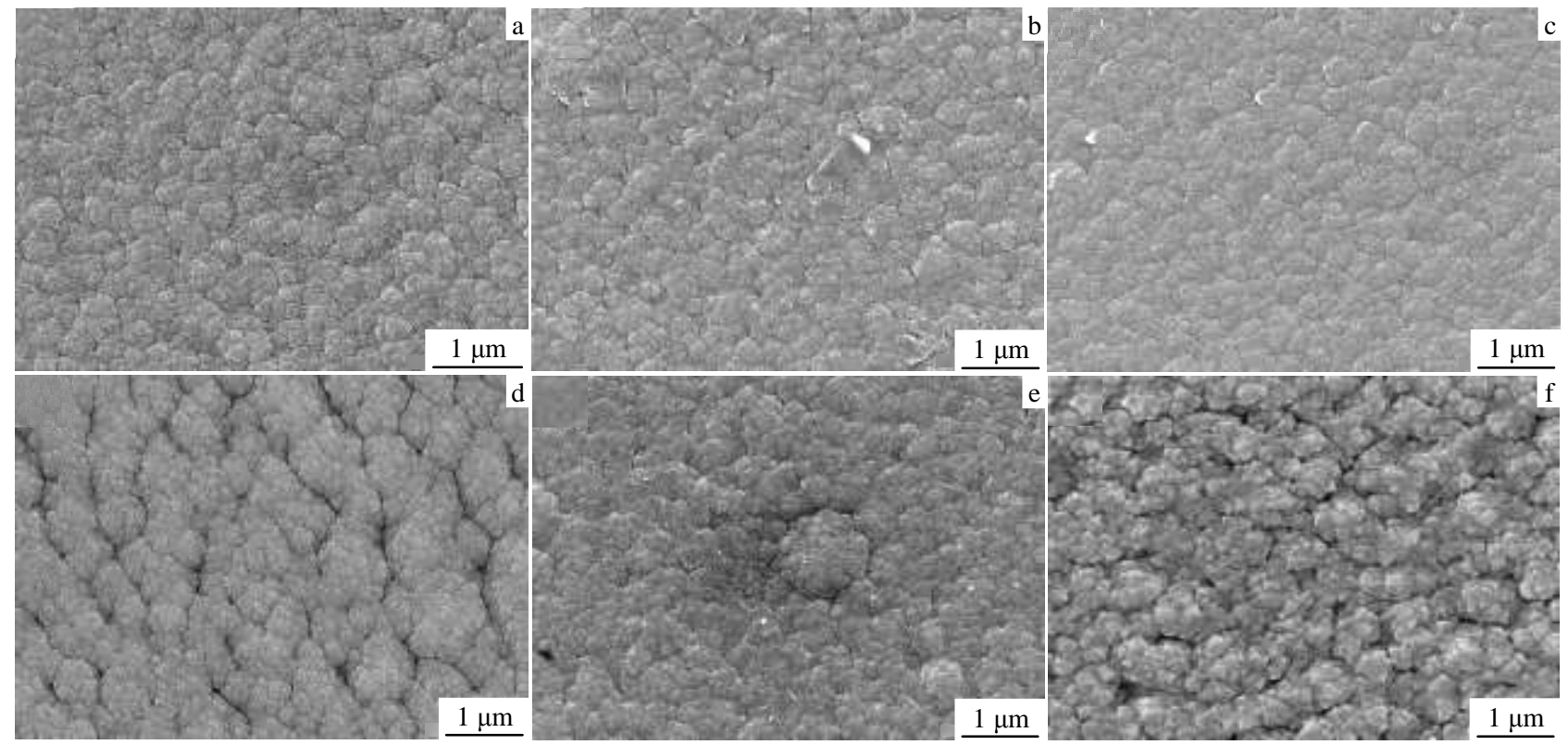

Fig. 1 Surface SEM morphologies of the coatings: (a) TiSiCN, (b) TiSiCON, (c) TiCrSiCN, (d) TiCrSiCON, (e) $\mathrm{CrSiCN}$, and (f) $\mathrm{CrSiCON}$
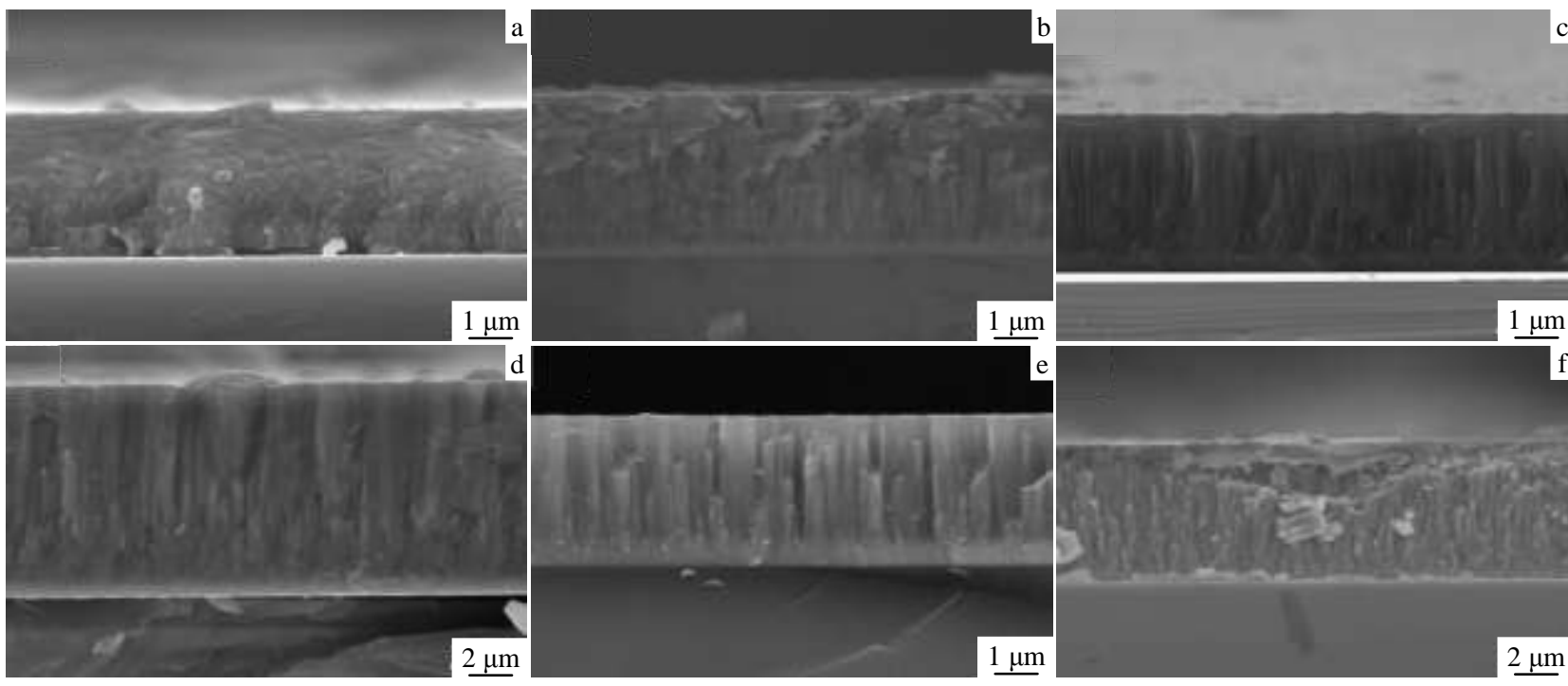

Fig. 2 Cross-sectional SEM morphologies of the coatings: (a) TiSiCN, (b) TiSiCON, (c) TiCrSiCN, (d) TiCrSiCON, (e) $\mathrm{CrSiCN}$, and (f) $\mathrm{CrSiCON}$

Fig. 1 and Fig. 2 also show that the coatings without oxygen (TiSiCN, TiCrSiCN and $\mathrm{CrSiCN}$ ) exhibit dense surface and cross-sectional morphology compared with the O-containing ones (TiSiCON, TiCrSiCON and CrSiCON). TiCrSiCN and CrSiCN coatings show more pronounced columnar microstructure than TiSiCN coating nearly throughout the entire thickness of the coating. The O-containing coating (TiCrSiCON and CrSiCON) surfaces show more obvious grain boundaries than the oxygen-free ones, and the defects between columnar crystals increase dramatically. Especially for the CrSiCON, the coating surface shows the most apparent defects at the grain boundary with large vacant position, compared with Ti-based TiSiCON and TiCr-based TiCrSiCON coatings.

\subsection{Phase compositions}

X-ray diffraction patterns of the coatings on $\mathrm{Si}(100)$ substrate are shown in Fig.3 and the chemical composition of $\mathrm{Ti}(\mathrm{Cr}) \mathrm{SiC}(\mathrm{O}) \mathrm{N}$ coatings is shown in Table 2. The diffraction peaks of TiSiCN and TiSiCON coatings are corresponding to face-centered cubic (fcc) $\mathrm{Ti}(\mathrm{C}) \mathrm{N}$, without apparent orientation. TiCrSiCN coating exhibits the combination of fcc $\mathrm{Cr}(\mathrm{C}) \mathrm{N}^{[19]}$ and $\operatorname{Ti}(\mathrm{C}) \mathrm{N}$ phase. 


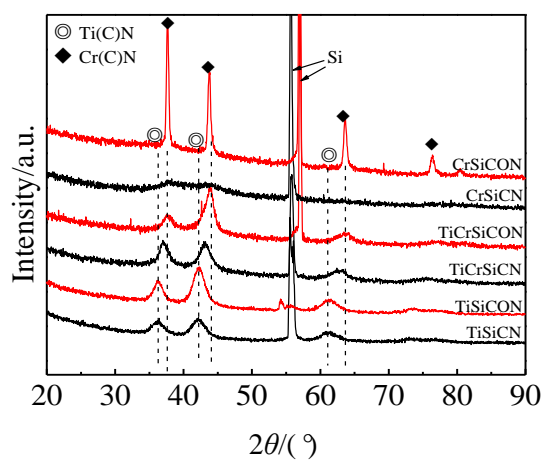

Fig. 3 XRD patterns of $\mathrm{Ti}(\mathrm{Cr}) \mathrm{SiC}(\mathrm{O}) \mathrm{N}$ coatings on $\mathrm{Si}(100)$ substrate

Table 2 Chemical composition of $\mathrm{Ti}(\mathrm{Cr}) \mathrm{SiC}(\mathrm{O}) \mathrm{N}$ coatings (at\%)

\begin{tabular}{ccccc}
\hline Coatings & $\mathrm{Ti}$ & $\mathrm{Cr}$ & $\mathrm{Si}$ & Others(C, N, O) \\
\hline TiSiCN & 41.48 & - & 11.89 & 46.63 \\
TiSiCON & 39.31 & - & 7.17 & 53.52 \\
TiCrSiCN & 20.13 & 23.62 & 11.44 & 44.81 \\
TiCrSiCON & 11.36 & 52.14 & 4.09 & 32.41 \\
CrSiCN & - & 48.56 & 11.56 & 39.88 \\
CrSiCON & - & 49.55 & 5.96 & 44.49 \\
\hline
\end{tabular}

While TiCrSiCON coating consists mostly of $\mathrm{Cr}(\mathrm{C}) \mathrm{N}$ phase, which is owing to the abundance of chromium in TiCrSiCON coating (Table 2). CrSiCN coating shows fairly weak peaks of $\mathrm{Cr}(\mathrm{C}) \mathrm{N}$ phase, which indicate large amorphous phase in $\mathrm{CrSiCN}$. CrSiCON coating shows a typical fcc $\mathrm{CrN}$ structure with narrow peaks compared with $\mathrm{CrSiCN}$ coating. In XRD results, there do not show any crystalline siliconcontaining phase, and this is similar to other literatures ${ }^{[20,21]}$. The XRD results show that no oxide crystals can be found, which indicates that the oxygen probably most exists in amorphous phase in the grain boundaries.

\subsection{Mechanical properties}

Fig. 4 shows the hardness $(H)$ and elastic modulus $(E)$ of these $\mathrm{Ti}(\mathrm{Cr}) \mathrm{SiC}(\mathrm{O}) \mathrm{N}$ coatings. The coatings without oxygen exhibit higher hardness than the O-containing coatings (TiSiCN vs TiSiCON, TiCrSiCN vs TiCrSiCON, CrSiCN vs $\mathrm{CrSiCON}$ ). For the TiSiCN and $\mathrm{CrSiCN}$ coatings, the addition of oxygen even decreases the hardness by more than half, which indicates that the existence of oxygen decreases the hardness significantly. Ti-based TiSiCN coating shows the maximum hardness of appropriately $25 \mathrm{GPa}$, while the maximum elastic modulus appears in Cr-based $\mathrm{CrSiCN}$ coating of $285 \mathrm{GPa}$. CrSiCON coating shows the minimum hardness of about $12.5 \mathrm{GPa}$ and a small elastic modulus of $196 \mathrm{GPa}$. The minimum elastic modulus appears in TiSiCON of $186 \mathrm{GPa}$. Therefore, we can conclude that the Ti-based coating shows higher hardness and lower elastic modulus ( TiSiCN vs CrSiCN, TiSiCON vs CrSiCON).

\subsection{Tribological properties and wear behavior}

The tribological properties of the $\mathrm{Ti}(\mathrm{Cr}) \mathrm{SiC}(\mathrm{O}) \mathrm{N}$ coatings are

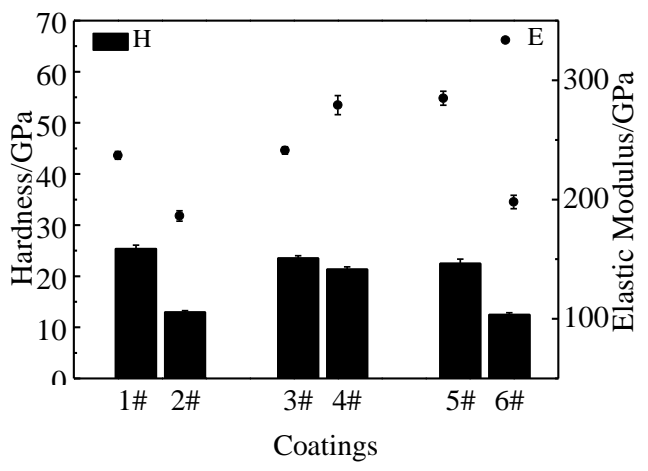

Fig. 4 Hardness and elastic modulus of $\mathrm{Ti}(\mathrm{Cr}) \mathrm{SiC}(\mathrm{O}) \mathrm{N}$ coatings (1\#-TiSiCN, 2\#-TiSiCON, 3\#-TiCrSiCN, 4\#-TiCrSiCON, $5 \#-\mathrm{CrSiCN}$, and 6\#-CrSiCON)

Table 3 Elastic recovery $\left(W_{\mathrm{e}}\right)$ of $\mathrm{Ti}(\mathrm{Cr}) \operatorname{SiC}(\mathrm{O}) \mathrm{N}$ coatings, friction coefficient and wear rate against $\mathrm{Al}_{2} \mathrm{O}_{3}$ balls

\begin{tabular}{ccc}
\hline Coatings & Friction coefficient & Wear rate $/ \times 10^{-7} \mathrm{~mm}^{3} \cdot \mathrm{N}^{-1} \cdot \mathrm{m}^{-1}$ \\
\hline TiSiCN & 0.21 & 15.30 \\
TiSiCON & 0.30 & 32.90 \\
TiCrSiCN & 0.67 & 29.06 \\
TiCrSiCON & 0.54 & 9.89 \\
CrSiCN & 0.42 & 13.50 \\
CrSiCON & 0.38 & 5.34 \\
\hline
\end{tabular}

researched by the pin-on-disc wear test. The typical optical morphology of the wear track and profile on the $\mathrm{Ti}(\mathrm{Cr}) \mathrm{SiC}(\mathrm{O}) \mathrm{N}$ coatings were studied by OM and surface profilometer. All the morphologies show apparent abrasion wear grooves, indicating that the wear mechanism for six coatings against $\mathrm{Al}_{2} \mathrm{O}_{3}$ is abrasive wear. The wear rates shown in Table 3 were calculated by integrating the profile of the wear track. When comparing all the six $\mathrm{Ti}(\mathrm{Cr}) \mathrm{SiC}(\mathrm{O}) \mathrm{N}$ coatings, there is no simple correlation between the wear rates and the friction coefficients. But between the same metal matrix coatings, the values of wear rate inversely correlation with the friction coefficients (TiSiCN vs. TiSiCON, TiCrSiCN vs. TiCrSiCON and $\mathrm{CrSiCN}$ vs. CrSiCON). For the Ti-based coating, the wear rate of TiSiCON exhibits 2 times more than that of TiSiCN. The existence of oxygen decreases the abrasive resistance remarkably in Ti-based TiSiCN coating. However, for the TiCr-based and Cr-based coatings, the addition of oxygen reduces the friction coefficients and the wear rates of coatings significantly. The wear rate of $\mathrm{TiCrSiCN}$ is 3 times larger than that of $\mathrm{TiCrSiCON}$. The wear rate of $\mathrm{CrSiCN}$ is about 2.5 times more than that of the $\mathrm{CrSiCON}$.

\section{Discussion}

In this part, the effect of oxygen on the structure and mechanical properties of coatings will be discussed. The surface morphology of O-containing coatings (TiCrSiCON and $\mathrm{CrSiCON}$ ) shows a porous feature with apparent defects 
(shown in Fig. 1d and Fig. 1f) and cross sectional structure with cracked and irregular columnar (shown in Fig. $2 \mathrm{~d}$ and Fig.2f). Emmerlich et al. ${ }^{[22]}$ have found that $\mathrm{O}$ is likely to react with $\mathrm{Si}$ and form $\mathrm{Si}-\mathrm{O}$ gaseous species during the diffusion of oxygen into the film. In the deposition process, the Si-O evaporation is likely to occur and leave these vacant positions at the grain boundaries. And indeed, the chemical compositions of $\mathrm{Ti}(\mathrm{Cr}) \mathrm{SiC}(\mathrm{O}) \mathrm{N}$ coatings (shown in Table 2) demonstrate that the $\mathrm{O}$-containing coatings contain less silicon contents than $\mathrm{O}$-free coatings.

Moreover, the oxygen which exists in coatings plays an important role on the 'nanocomposite' microstructure. The silicon in Me-Si-N coatings (without oxygen) always appears to be amorphous $\mathrm{Si}_{3} \mathrm{~N}_{4}$ phase in the grain boundaries. The existence of a certain amount of silicon could increase the amorphous phase and reduce grain coarsening in TiSiCN coating $^{[23,24]}$.

While, the addition of oxygen would prevent this refining process by reducing the amount of $\mathrm{Si}_{3} \mathrm{~N}_{4}$, possibly because of the electronic effect, the strong electron affinity of oxygen is probably to weaken the $\mathrm{Si}-\mathrm{N}$ bonds, and forming silicon oxynitride ( $\mathrm{Si}-\mathrm{O}-\mathrm{N})$ or other oxide in the gain boundaries with lower hardness than $\mathrm{Si}_{3} \mathrm{~N}_{4}{ }^{[25]}$.

Thus, the adverse influence of oxygen on microstructure of coatings is likely to destroy the structure of nanocomposite nc$\mathrm{MeN} / \mathrm{a}-\mathrm{Si}_{3} \mathrm{~N}_{4}$ and form porous grain boundaries with oxides. So the hardness of O-containing coatings (TiSiCON, TiCrSiCON and $\mathrm{CrSiCON}$ ) was decreased obviously. Actually, for the O-containing coatings, the oxidation of Ti element (or $\mathrm{Cr}$ ) cannot be ignored during the growth of coatings. The oxidation of different atoms at the high-temperature could be used as reference. Ti atoms oxidized rapidly to semi-protective $\mathrm{TiO}_{2}$, while $\mathrm{Si}$ usually oxidized to the extremely protective $\mathrm{SiO}_{2}$ with low diffusivity for both anions and cations. The phenomenon that $\mathrm{TiO}_{2}$ grew at more accelerated rate than the $\mathrm{SiO}_{2}$ in the process of oxidation was also found in other study ${ }^{[26]}$. While the formation of $\mathrm{SiO}_{2}$ was easier and earlier than $\mathrm{Cr}_{2} \mathrm{O}_{3}$ with the increasing of oxygen during the growth of films ${ }^{[27]}$. For these reasons, it can be speculated that the $\mathrm{TiO}_{2}$ would be more than the amount of $\mathrm{SiO}_{2}$ in TiSiCON coating. While for the TiCrSiCON and CrSiCON coatings with noble $\mathrm{Cr}$, the reactively active $\mathrm{Si}$ probably formed more $\mathrm{SiO}_{2}$. In order to clarify the existing state of oxides phase in the oxygen-containing coatings, the high resolution XPS spectra of $\mathrm{O}$ and $\mathrm{Si}$ elements for two TiSiCON and $\mathrm{CrSiCON}$ coatings were studied. The results showed more $\mathrm{SiO}_{2}$ in $\mathrm{CrSiCON}$ coating. And it has been proved that $\mathrm{SiO}_{2}$ phase can act as lubricant in the friction process ${ }^{[28]}$. Therefore, for the O-containing TiCrSiCON and CrSiCON coatings, probably because the more $\mathrm{SiO}_{2}$ phase acts as lubricant, the friction coefficient and wear rate significantly decline to a small value than $\mathrm{TiCrSiCN}$ and $\mathrm{CrSiCN}$, respectively. While for the Ti-based TiSiCON coating, both the friction coefficient and the wear rate are higher than that of TiSiCN coating. Probably without enough lubricant $\mathrm{SiO}_{2}$ phase, drawback of the loose structure and cracked columnar crystal of TiSiCON coating become the main influence factors in friction and wear.

\section{Conclusions}

1) TiSiCN, TiSiCON, TiCrSiCN, TiCrSiCON, CrSiCN and $\mathrm{CrSiCON}$ coatings are deposited on WC-Co substrates and $\mathrm{Si}$ wafers by PEMS technique.

2) The existence of oxygen would induce loose surface structure for TiSiCON, TiCrSiCON and CrSiCON coatings, which is likely ascribed to the evaporation of $\mathrm{Si}-\mathrm{O}$ gaseous species in deposition process. And oxygen in the grain boundaries would hinder the refining grain effect of Si element and create more defects, through forming $\mathrm{Si}-\mathrm{O}-\mathrm{N}$ (or $\mathrm{Si}-\mathrm{O}$ ) bond.

3) The oxygen-containing TiSiCON, TiCrSiCON and CrSiCON coatings still exhibit a face center cubic (fcc) TiN-type (CrN-type) structure. The addition of oxygen element would decrease the hardness and elasticity of coatings. The addition of oxygen would form amorphous oxygen compounds $\mathrm{SiO}_{2}$, which could act as lubricant for TiCr-based TiCrSiCON and $\mathrm{Cr}$-based $\mathrm{CrSiCON}$ coatings during friction and wear, and reduce the friction coefficient and wear rate when compared with $\mathrm{TiCrSiCN}$ and $\mathrm{CrSiCN}$, respectively. But, for Ti-based TiSiON coating, the wear rate increases significantly probably because of fewer lubricant $\mathrm{SiO}_{2}$ oxides and the loose structure. Acknowledgements: The authors would like to thank Prof. R.H. Wei (Southwest Research Institute, San Antonio, USA) for his technical assistance on fabricating coating.

\section{References}

1 Veprek S, Veprek-Heijman M G J. Surface and Coatings Technology[J], 2007, 201(13): 6064

2 Musil J, Vlcek J. Surface and Coatings Technology[J], 2001, 142: 557

3 Choi S R, Park I W, Kim S H et al. Thin Solid Films[J], 2004, 447: 371

4 Wang Q M, Kim K H. Acta Materialia[J], 2009, 57(17): 4974

5 Veprek S, Haussmann M, Reiprich S. Journal of Vacuum Science \& Technology $A[\mathrm{~J}], 1996,14(1): 46$

6 Veprek S, Veprek-Heijman M J G. Surface and Coatings Technology[J], 2008, 202(21): 5063

7 Veprek S, Zhang R F, Veprek-Heijman M G J et al. Surface and Coatings Technology[J], 2010, 204(12): 1898

8 Flink A, Larsson T, Sjölén J et al. Surface and Coatings Technology[J], 2005, 200(5): 1535

9 Zhang R F, Veprek S. Materials Science and Engineering A[J], 2006, 424(1): 128

10 Choi J B, Cho K, Lee M H et al. Thin Solid Films[J], 2004, 447: 365

11 Lin J, Wang B, Ou Y et al. Surface and Coatings Technology[J], 2013, 216: 251 
12 Shirahata J, Ohori T, Asami H et al. Thin Solid Films[J], 2011, 519(11): 3497

13 Minami T, Nishio S, Murata Y. Surface and Coatings Technology [J], 2014, 254: 402

14 Hao S, Delley B, Veprek S et al. Physical Review Letters[J], 2006, 97(8): 086102

15 Ding X Z, Zeng X T, Liu Y C et al. Journal of Vacuum Science \& Technology A: Vacuum, Surfaces, and Films[J], 2006, 24(4): 974

16 Li Q, Jiang F, Leng Y et al. Vacuum[J], 2013, 89: 168

17 Wei R. Surface and Coatings Technology[J], 2008, 203(5): 538

18 El-Rahman A M A, Wei R. Surface and Coatings Technology[J], 2014, 258: 320

19 Cekada M, Panjan P, Macek M et al. Surface and Coatings Technology[J], 2002, 151: 31

20 Benkahoul M, Robin P, Gujrathi S C et al. Surface and Coatings Technology[J], 2008, 202(16): 3975

21 Camps I, Muhl S, Camps E et al. Surface and Coatings
Technology[J], 2014, 255: 74

22 Emmerlich J, Music D, Eklund P et al. Acta Materialia[J], 2007, 55(4): 1479

23 Thangavel E, Lee S, Nam K S et al. Applied Surface Science[J], 2013, 265: 60

24 Bendavid A, Martin P J, Cairney J et al. Applied Physics A[J], 2005, 81(1): 151

25 Veprek S, Karvankova P, Veprek-Heijman M G J. Journal of Vacuum Science \& Technology B: Microelectronics and Nanometer Structures[J], 2005, 23(6): L17

26 Chang Y Y, Hsiao C Y. Surface and Coatings Technology[J], 2009, 204(6): 992

27 Lee J D, Wang Q M, Kim S H et al. Surface and Coatings Technology[J], 2012, 206(18): 3721

28 Shin S H, Kim M W, Kang M C et al. Surface and Coatings Technology[J], 2008, 202(22): 5613

\title{
等离子体增强磁控溅射制备 $\mathrm{Ti}(\mathrm{Cr}) \mathrm{SiC}(\mathrm{O}) \mathrm{N}$ 涂层的结构和力学性能研究
}

\author{
辛 欣, 张腾飞, 王 愉, 喻 燕, 冷永祥, 谢 东, 黄 楠 \\ (西南交通大学 材料先进技术教育部重点实验室, 四川 成都 610031)
}

\begin{abstract}
摘 要: 采用等离子体增强磁控溅射(PEMS)方法分别在硬质合金和硅片上制备了 TiSiCN, TiSiCON, TiCrSiCN, TiCrSiCON, CrSiCN 和 CrSiCON 涂层。采用 XRD、SEM、EDS、显微硬度计及销盘式摩擦磨损试验机对含氧涂层和不含氧涂层的微观结构、成分和力学性能 进行了研究。结果表明, TiSiCON, TiCrSiCON 和 CrSiCON 含氧涂层为 TiN 型(或 CrN 型)面心立方(fcc)结构, 但是 $\mathrm{TiSiCON}$, TiCrSiCON 和 $\mathrm{CrSiCON}$ 涂层中氧的存在会导致产生疏松结构, 与不含氧涂层 $\mathrm{TiSiCN}, \mathrm{TiCrSiCN}$ 和 $\mathrm{CrSiCN}$ 相比具有更多的缺陷; 氧的加入会导致 $\mathrm{Ti}(\mathrm{Cr}) \mathrm{SiCN}$ 涂层硬度和弹性的下降; $\mathrm{TiCrSiCON}$ 和 $\mathrm{CrSiCON} 2$ 种含氧涂层相对于不含氧涂层 $\mathrm{TiCrSiCN}$ 和 $\mathrm{CrSiCN}$ 具有更低的摩擦系数 和磨损率; 然而, TiSiCON 相对于 TiSiCN 却表现出更高的摩擦系数和磨损率。
\end{abstract}

关键词： $\mathrm{Ti}(\mathrm{Cr}) \mathrm{SiC}(\mathrm{O}) \mathrm{N}$; 含氧涂层; 微观结构; 硬度; 磨损

作者简介: 辛 欣, 女, 1992 年生, 硕士, 西南交通大学材料科学与工程学院, 四川 成都 610031, E-mail: xin_xin127@126.com 